\title{
Isolated ascending aorta dilatation is associated with increased risk of abdominal aortic aneurysm
}

Enrique Gallego-Colon ${ }^{1 *}$, Chaim Yosefy ${ }^{1}$, Evgenia Cherniavsky², Azriel Osherov ${ }^{1}$, Vladimir Khalameizer ${ }^{1}$, Xavier Piltz ${ }^{2}$, Marina Pery', Sharon Bruoha ${ }^{1}$ and Jamal Jafari ${ }^{1}$

\begin{abstract}
Background: Abdominal aortic aneurysm (AAA) is an asymptomatic condition characterized by progressive dilatation of the aorta. The purpose of this study is to identify important 2D-TTE aortic indices associated with AAA as predictive tools for undiagnosed AAA.

Methods: In this retrospective study, we evaluated the size of the ascending aorta in patients without known valvular diseases or hemodynamic compromise as predictive tool for undiagnosed AAA. We studied the tubular ascending aorta of 170 patients by 2-dimensional transthoracic echocardiography (2D-TTE). Patients were further divided into two groups, 70 patients with AAA and 100 patients without AAA with normal imaging results.

Results: Dilatation of tubular ascending aorta was measured in patients with AAA compared to the group with absent AAA (37.5 $\pm 4.8 \mathrm{~mm}$ vs. $31.2 \pm 3.6 \mathrm{~mm}, p<0.001$, respectively) and confirmed by computed tomographic (CT) (35.6 \pm $5.1 \mathrm{~mm}$ vs. $30.8 \pm 3.7 \mathrm{~mm}, p<0.001$, respectively). An increase in tubular ascending aorta size was associated with the presence of AAA by both 2D-TTE and CT ( $r=0.40, p<0.001$ and $r=0.37, p<0.001$, respectively). The tubular ascending aorta (D diameter) size of $\geq 33 \mathrm{~mm}$ or $\geq 19 \mathrm{~mm} / \mathrm{m}^{2}$ presented with $2-4$ times more risk of AAA presence (OR $4.68, \mathrm{Cl}$ $2.18-10.25, p=0.001$ or $\mathrm{OR} 2.63, \mathrm{Cl} 1.21-5.62, p=0.02$, respectively). In addition, multiple logistic regression analysis identified tubular ascending aorta (OR 1.46, $p<0.001$ ), age (OR 1.09, $p=0.013$ ), gender (OR 0.12, $p=0.002$ ), and LVESD (OR 1.24, $p=0.009$ ) as independent risk factors of AAA presence.

Conclusions: An increased tubular ascending aortic diameter, measured by 2D-TTE, is associated with the presence of AAA. Routine 2D-TTE screening for silent AAA by means of ascending aorta analysis, may appear useful especially in older patients with a dilated tubular ascending aorta $(\geq 33 \mathrm{~mm})$.
\end{abstract}

Keywords: Abdominal aortic aneurysm, Aortic dilatation, Screening, Computed tomography, Transthoracic echocardiography

\section{Background}

Abdominal aortic aneurysm (AAA) is a local dilatation of the abdominal aorta exceeding the normal diameter by $50 \%$, or a dilatation of more $\geq 30 \mathrm{~mm}$ in size [1].

\footnotetext{
* Correspondence: enrique.gce@gmail.com

${ }^{1}$ Cardiology Department, Barzilai Medical Center Campus, Barzilai University Medical Center, Ben-Gurion University, Ashkelon, Israel

Full list of author information is available at the end of the article
}

Commonly diagnosed in the fifth decade of life, AAA displays slow and variable rate of progression or remains stable for several years. The AAA prevalence can range from $1.3 \%$ in men aged $55-64,9.1 \%$ in patients between 65 and 74 and $16.8 \%$ in patients between 75 and 84 , and $22.0 \%$ in patients $\geq 85$ year [2]. Smoking, hypertension, elevated cholesterol levels, and obesity are among the most common modifiable risk factors [3-5]. The current

(c) The Author(s). 2021 Open Access This article is licensed under a Creative Commons Attribution 4.0 International License, which permits use, sharing, adaptation, distribution and reproduction in any medium or format, as long as you give appropriate credit to the original author(s) and the source, provide a link to the Creative Commons licence, and indicate if changes were made. The images or other third party material in this article are included in the article's Creative Commons licence, unless indicated otherwise in a credit line to the material. If material is not included in the article's Creative Commons licence and your intended use is not permitted by statutory regulation or exceeds the permitted use, you will need to obtain permission directly from the copyright holder. To view a copy of this licence, visit http://creativecommons.org/licenses/by/4.0/ The Creative Commons Public Domain Dedication waiver (http://creativecommons.org/publicdomain/zero/1.0/) applies to the data made available in this article, unless otherwise stated in a credit line to the data. 
U.S. Preventive Services Task Force (USPSTF) recommendation statement on screening for abdominal aortic aneurysm, recommends 1-time screening for AAA with ultrasonography in men aged 65 to 75 years who have ever smoked (B recommendation) [6]. However, a recent study by Carnevale and collaborators emphasized the need of expanding the established USPSTF screening guidelines to include the expanded Society for Vascular Surgery (SVS) criteria which may potentially double the number of patients identified with AAA [7]. Since abdominal aortic dilatation is usually asymptomatic, and screening programs are not widely implemented, aneurysm of the aorta is usually discovered incidentally or upon rupture. In those patients suffering from a ruptured abdominal aortic aneurysm, the mortality rate is between 60 and $80 \%$, with an additional elevated operative mortality [8-11].

In this study, we evaluated the utility of the ascending aorta examination by 2D-TTE for AAA screening. In addition, we aimed to identify important 2D-TTE aortic indices associated with AAA as predictive tools for undiagnosed AAA. The identification of patients with altered aortic indices that can raise the suspicion of AAA during routine 2D-TTE could prompt immediate AAA evaluation.

\section{Methods}

\section{Cohort description}

For this retrospective study, we analyzed detailed patient data from 2012 to 2019 retrieved from a picture archiving computer system (PACS) database. Patients diagnosed with AAA by computed tomographic (CT) imaging that also underwent 2D-TTE were selected for this study. Aneurysm of the abdominal aorta was defined as an abdominal aorta diameter of $\geq 3 \mathrm{~cm}$ or an aortic diameter 1.5 times larger than the adjacent segment based on current guidelines [11]. The study population included $170 \mathrm{pa}$ tients divided into two groups, 70 patients with diagnosed AAA and 100 patients without AAA (absent AAA group) with normal imaging results. The exclusion criteria included patients with dilated ascending aorta due to cardiac abnormalities, valvular disease (e.g.: aortic stenosis or regurgitation), post-stenotic dilatation, mechanical or infected valves, aortic dissection and connective tissue disorders (e.g.: Marfan syndrome, Ehlers-Danlos syndrome, or bicuspid valve). Diabetes mellitus was defined as $\mathrm{HbA} 1 \mathrm{c} \geq 6.5 \%$, or fasting plasma glucose level $\geq 126$ $\mathrm{mg} / \mathrm{dL}$ in three separate measurements. The study protocol adhered to the Declaration of Helsinki and was approved by the institutional review board of Barzilai Medical Center (BRZ-0090-20).

\section{2-dimensional transthoracic echocardiography}

Routine echocardiographic evaluation was performed by three registered sonographers (C.Y., X.P., and M.P.) according to the recommended guidelines [12, 13]. The thoracic aorta, from the aortic annulus to the innominate artery, was measured at the aortic annulus (A diameter), at the sinus of Valsalva (B diameter), at the sinotubular junction ( $\mathrm{C}$ diameter), and at the proximal (tubular) ascending aorta (D diameter) (Fig. 1) [13]. The aortic annulus (A diameter) was analyzed to evaluate valvular dilatation as part of the exclusion criteria. Changes in the tubular ascending aorta ( $\mathrm{D}$ diameter) were measured at the level of the ascending aorta, $3 \mathrm{~cm}$ above the aortic valve [13]. The echocardiographic measurements were obtained in standard parasternal long axis views and normalized for the body surface area [13]. The aortic diameter was measured from inner edge-to-inner edge during diastole to increase reproducibility. To reduce overestimation of actual dimensions, the aorta was measured along the axis perpendicular to its long axis, to avoid obtaining an oblique imaging plane. All routine echocardiography exams employed an EPIQ 7 and iE33 echocardiographic machine (Philips Medical Systems, Andover, MA). All images were digitally stored for offline analysis (QLAB 10.0 cardiac 3DQ, Philips Medical Systems).

\section{Computed-tomographic angiography}

CT angiography of the abdominal aorta was performed using a 64-channel MDCT (Brilliance, Philips, Eindhoven, Holland), which covered the region between the thoracic inlet and the common femoral arteries. The thoracic aorta, from the aortic annulus to the innominate artery, was measured at the aortic annulus (A diameter), at the sinus of Valsalva (B diameter), at the sinotubular junction ( $\mathrm{C}$ diameter), and at the proximal (tubular) ascending aorta (D diameter) (Fig. 1) [13]. An average value for the abdominal aortic diameter was calculated for infra and/or suprarenal aneurysm presentation. The pre-contrast phase was acquired with a collimation of $2.5 \mathrm{~mm}, 120 \mathrm{kVp}$, and $320 \mathrm{mAs}$. The arterial and venous post-contrast phases were both acquired with $0.625 \mathrm{~mm}$ slice collimation, a helical pitch of 0.703 , a tube rotation velocity of 0.5 per second, tube voltage $120 \mathrm{kVp}$, and planned tube current-time product $350 \mathrm{mAs}$; reconstructed to a $1.0-\mathrm{mm}$ slice thickness.

\section{Statistical analysis}

The results are presented as the mean \pm standard deviation (SD) for continuous variables with normal distribution, and as number and percentage of total patients for categorical data. T-test or one-way Analysis of Variance (ANOVA) with Bonferroni's multiple comparison tests was used for comparison of continuous variables. Proportions were compared with contingency tables followed by the chi-square test. Pearson's statistics were used to assess the relationship between variables. Multiple logistic regression analysis was used to ascertain 
(A)

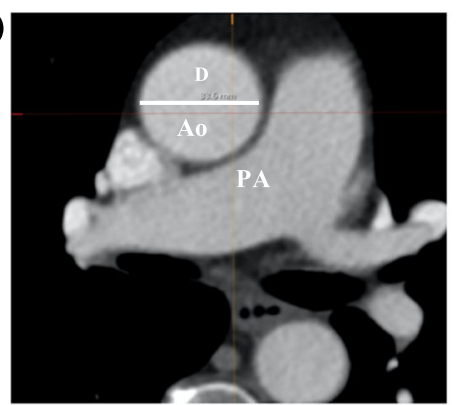

(B)

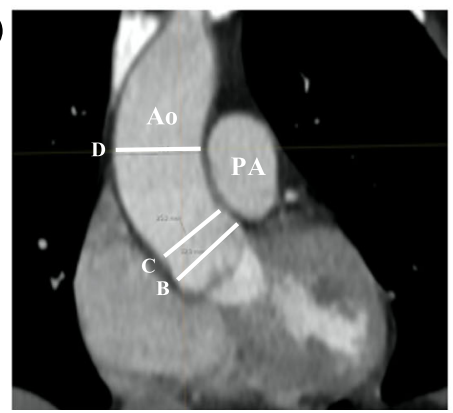

(D)

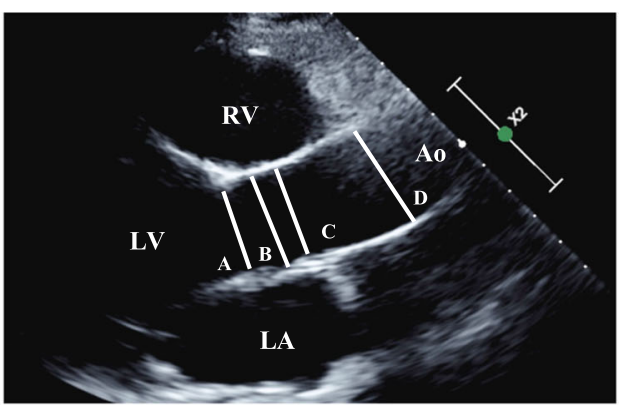

(C)

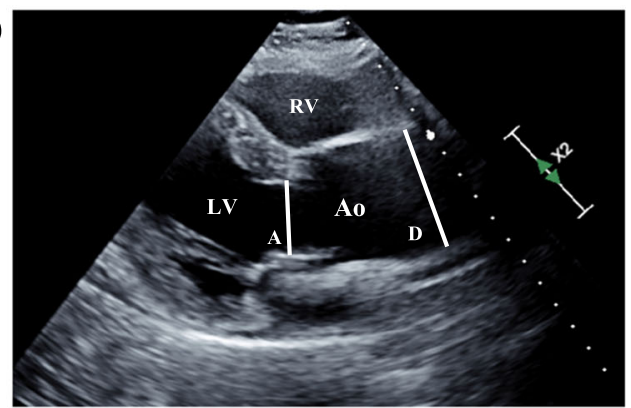

Fig. 1 Cardiovascular imaging of the ascending aorta by (a and $\mathbf{b}$ ) computed-tomography and by (c and $\mathbf{d}$ ) 2D-transthoracic echocardiography. Aortic annulus ( $D$ diameter). Sinuses of Valsalva (B diameter). Sinotubular junction (C diameter). Proximal (tubular) ascending aorta (D diameter). $\mathrm{PA}$, pulmonary artery. Ao, Aorta. RV, right ventricle. LV, left ventricle

independent variables associated with AAA. The results are presented as the odds ratio (OR) with a $95 \%$ confidence interval $(\mathrm{CI})$. A two-sided $p$-value $<0.05$ was considered statistically significant. Statistical analysis was performed with SPSS software version 21.0 statistical package (SPSS IBM. Inc.).

\section{Results}

We analyzed data from 170 patients divided into two groups, the AAA group comprised of 70 patients diagnosed with AAA and, the control group without AAA (No AAA group) comprised of 100 patients (Table 1). No significant differences in age, body mass index, body

Table 1 Clinical characteristics of the cohort

\begin{tabular}{|c|c|c|c|}
\hline \multirow[t]{2}{*}{ Variable } & \multicolumn{2}{|c|}{ Abdominal Aortic Aneurysm (AAA) } & \multirow{2}{*}{$\begin{array}{l}p \text { - } \\
\text { value }\end{array}$} \\
\hline & $\begin{array}{l}\text { Control } \\
\text { No AAA }(n=100)\end{array}$ & AAA $(n=70)$ & \\
\hline \multicolumn{4}{|l|}{ Patient characteristics } \\
\hline Age (years), mean $\pm S D$ & $74.43 \pm 12.86$ & $77.97 \pm 9.47$ & 0.053 \\
\hline Women, n (\%) & $52(52)$ & $10(14.2)$ & 0.001 \\
\hline $\mathrm{BMI}$, mean $\pm \mathrm{SD}$ & $22.3 \pm 3.85$ & $22.16 \pm 3.53$ & 0.83 \\
\hline $\mathrm{BSA}\left(\mathrm{m}^{2}\right)$, mean $\pm \mathrm{SD}$ & $1.77 \pm 0.21$ & $1.83 \pm 0.18$ & 0.09 \\
\hline Heart Rate & $74.68 \pm 17.19$ & $68.15 \pm 14.42$ & 0.07 \\
\hline \multicolumn{4}{|l|}{ Comorbidities } \\
\hline Hypertension, n (\%) & $55(55)$ & $59(84)$ & 0.001 \\
\hline Dyslipidemia, n (\%) & $42(42)$ & $50(71)$ & 0.001 \\
\hline Stroke, n (\%) & $10(10)$ & $15(21)$ & 0.05 \\
\hline Ischemic heart disease, n (\%) & $21(21)$ & $49(70)$ & 0.001 \\
\hline Peripheral vascular diseases, n (\%) & $3(3)$ & $17(24)$ & 0.001 \\
\hline Current smoker, n (\%) & $15(15)$ & $15(21)$ & 0.31 \\
\hline Diabetes mellitus, n (\%) & $16(16)$ & $21(30)$ & 0.04 \\
\hline
\end{tabular}


surface area and heart rate between the two groups were observed (Table 1). Compared to the control group, patients with AAA were older $(74.43 \pm 12.86$ vs. $77.97 \pm$ 9.47, $p=0.053)$ with higher prevalence of hypertension (55\% vs. $84 \% ; p<0.001)$, altered lipid profile $(42 \%$ vs. $71 \% ; p<0.001)$, stroke (10\% vs. $21 \% ; p=0.05)$, ischemic heart disease $(21 \%$ vs. $70 \%, p<0.001)$, peripheral vascular disease ( $3 \%$ vs. $24 \%, p<0.001)$, and diabetes $(16 \%$ vs. $30 \%, p=0.04)$ (Table 1).

Clinical and 2D-TTE measurements in patients with or without AAA are shown in Table 2. No significant differences were observed in left ventricular end diastolic diameter, intraventricular septal thickness, right ventricular end diastolic diameter, left atrium (LA)-AP diameter, LA area, right atrium (RA), E/E' and E/A ratio between the two groups. Conversely, left ventricular end systolic diameter $(29.4 \pm 4.4 \mathrm{~mm}$ vs. $37.5 \pm 9.4$ $\mathrm{mm} ; p=0.005$, Table 2) and left ventricular ejection fraction $(60.4 \pm 3.9 \%$ vs. $50.0 \pm 6.5 \% ; p<0.001)$ were significantly higher in the AAA group than in the control group (No AAA group) (Table 2). No significant differences in ascending aorta values were observed when both 2D-TTE and CT imaging studies were compared (Figure Sup. 1). Abdominal aortic values revealed an average aneurysm of $\geq 30 \mathrm{~mm}$ in the AAA group when compared to the control group $(18.9 \pm 3.2$

Table 2 Comparison of echocardiographic characteristics

\begin{tabular}{|c|c|c|c|}
\hline \multirow[t]{2}{*}{ Variable } & \multicolumn{2}{|l|}{ Abdominal Aortic Aneurysm } & \multirow{2}{*}{$\begin{array}{l}p- \\
\text { value }\end{array}$} \\
\hline & Control No AAA $(n=100)$ & AAA $(n=70)$ & \\
\hline \multicolumn{4}{|c|}{ Standard echocardiographic measurements } \\
\hline LVEDD $(\mathrm{mm})$, mean $\pm \mathrm{SD}$ & $45.6 \pm 4.7$ & $52.0 \pm 7.0$ & 0.07 \\
\hline LVESD (mm), mean \pm SD & $29.4 \pm 4.4$ & $37.5 \pm 9.4$ & 0.005 \\
\hline IVS $(\mathrm{mm})$, mean $\pm \mathrm{SD}$ & $10.32 \pm 1.8$ & $11.6 \pm 1.7$ & 0.99 \\
\hline $\operatorname{LVEF}(\%)$, mean $\pm S D$ & $60.4 \pm 3.9$ & $50.0 \pm 6.5$ & 0.001 \\
\hline RVEDD $(\mathrm{mm})$, mean $\pm \mathrm{SD}$ & $35.8 \pm 5.1$ & $40.3 \pm 6.5$ & 0.51 \\
\hline LA-AP $(\mathrm{mm})$, mean $\pm S D$ & $36.5 \pm 6.8$ & $40.2 \pm 7.1$ & 0.72 \\
\hline $\mathrm{LA}$ area $(\mathrm{mm})$, mean $\pm \mathrm{SD}$ & $20 \pm 5.5$ & $24.5 \pm 7$ & 0.51 \\
\hline $\mathrm{RA}$ area $(\mathrm{mm})$, mean $\pm \mathrm{SD}$ & $16.1 \pm 5.1$ & $19.3 \pm 6.8$ & 0.86 \\
\hline$E / E^{\prime}$ & $9.1 \pm 4.1$ & $11.2 \pm 4.1$ & 0.99 \\
\hline E/A ratio & $1 \pm 0.4$ & $0.9 \pm 0.6$ & 0.99 \\
\hline \multicolumn{4}{|c|}{ Ascending aorta measurements by $2 \mathrm{D}-\mathrm{TTE}$} \\
\hline Aortic annulus, A, (mm) & $19.8 \pm 1.6$ & $20.8 \pm 1.4$ & 0.67 \\
\hline Aortic annulus, $A,(\mathrm{~mm} / \mathrm{m} 2)$ & $11.3 \pm 1.3$ & $11.4 \pm 1.1$ & 0.99 \\
\hline Sinus of Valsalva, B, (mm) & $30.6 \pm 4.3$ & $32.7 \pm 6.2$ & 0.051 \\
\hline Sinus of Valsalva, $B,(\mathrm{~mm} / \mathrm{m} 2)$ & $17.3 \pm 2.6$ & $17.8 \pm 3.8$ & 0.72 \\
\hline Sinotubular junction, C, (mm) & $25.3 \pm 4.5$ & $27.3 \pm 4.9$ & 0.08 \\
\hline Sinotubular junction, C, (mm/m2) & $14.3 \pm 2.4$ & $14.8 \pm 2.9$ & 0.64 \\
\hline Tubular ascending aorta, D, (mm) & $31.2 \pm 3.6$ & $37.5 \pm 4.8$ & 0.001 \\
\hline Tubular ascending aorta, $\mathrm{D},(\mathrm{mm} / \mathrm{m} 2)$ & $17.7 \pm 2.7$ & $20.4 \pm 3.0$ & 0.001 \\
\hline \multicolumn{4}{|c|}{ Ascending and abdominal aorta measurements by $\mathrm{CT}$} \\
\hline Sinus of Valsalva, B, (mm) & $31.5 \pm 3.1$ & $33.8 \pm 5.2$ & 0.07 \\
\hline Sinus of Valsalva, $B,(\mathrm{~mm} / \mathrm{m} 2)$ & $18.1 \pm 2.9$ & $18.5 \pm 3.3$ & 0.96 \\
\hline Sinotubular junction, C, (mm) & $26.4 \pm 3.2$ & $27.9 \pm 4.7$ & 0.37 \\
\hline Sinotubular junction, C, (mm/m2) & $15.1 \pm 2.5$ & $15.2 \pm 2.9$ & 0.99 \\
\hline Tubular ascending aorta, D, (mm) & $30.8 \pm 3.7$ & $35.6 \pm 5.1$ & 0.001 \\
\hline Tubular ascending aorta, $\mathrm{D},(\mathrm{mm} / \mathrm{m} 2)$ & $17.7 \pm 3.0$ & $19.3 \pm 3.1$ & 0.045 \\
\hline Abdominal aorta (mm) & $18.9 \pm 3.2$ & $35.5 \pm 10$ & 0.001 \\
\hline Abdominal aorta (mm/m2) & $10.7 \pm 2$ & $19.4 \pm 6.4$ & 0.0001 \\
\hline
\end{tabular}

LVEDD Left ventricle end diastolic diameter. LVESD Left ventricle end systolic diameter. IVS Interventricular septum. LVEF Left ventricle ejection fraction. RVEDD Right ventricle end diastolic diameter. $L A-A P$ Left atrial anterior-posterior diameter. $L A$ Area Left atrial area. RA Area Right atrial area. E/A Early to late mitral flow. $C T$ Computed tomography scan. 2D-TTE 2-Dimensional transthoracic echocardiography 
(A)

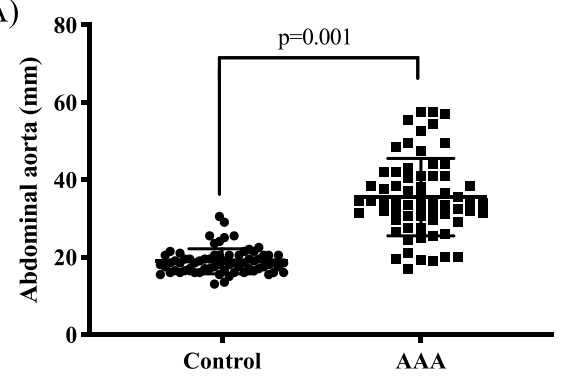

(C)

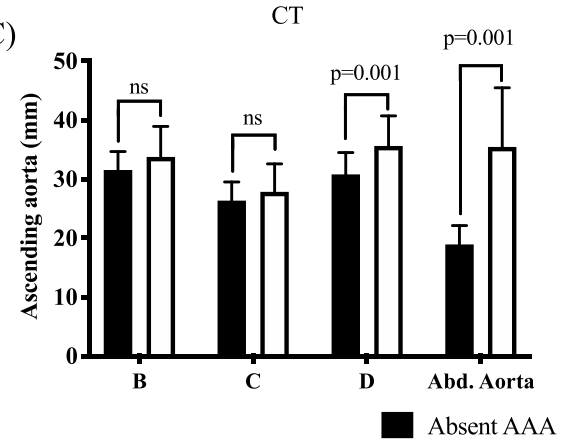

(B)

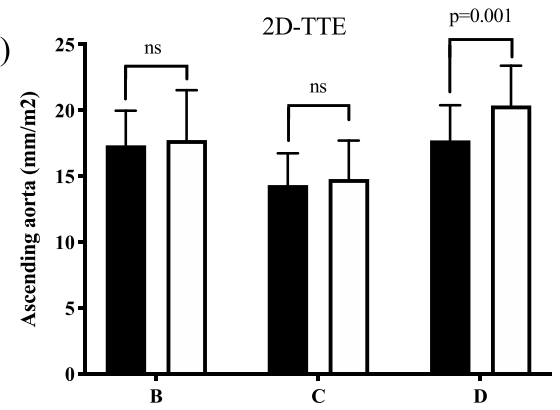

(D)

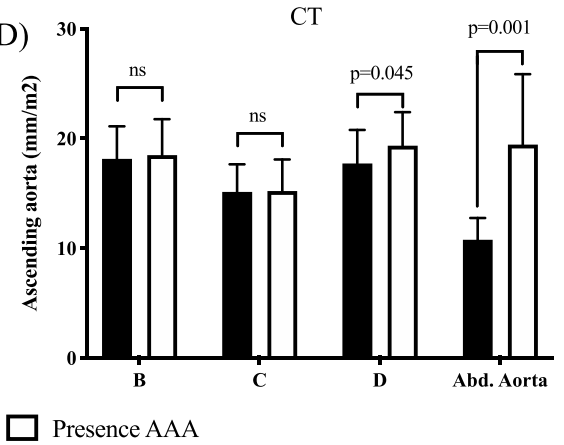

Fig. 2 Analysis of tubular ascending aorta diameters in patients with presence of abdominal aortic aneurysm (AAA) and absence AAA. a Abdominal aortic diameter in presence (AAA group) and absence (Control group) of AAA. Difference in ascending aorta diameters by (b) 2Dtransthoracic echocardiography and (c and $\mathbf{d}$ ) CT scan in the absence (black) and presence (white) of AAA. Sinuses of Valsalva (B diameter). Sinotubular junction (C diameter). Abd. aorta, abdominal aorta

$\mathrm{mm}$ vs. $35.5 \pm 10 \mathrm{~mm}, p<0.001$; Fig. $2 \mathrm{a}$ and Table 2). Interestingly, 2D-TTE analyses of the ascending aorta showed significant differences between patients with and without AAA. Compared to the control group, the 2D-TTE analyses of the ascending aorta indicated a dilatation at the level of the tubular ascending aorta (D diameter) in patients diagnosed with AAA (31.2 \pm $3.6 \mathrm{~mm}$ vs. $37.5 \pm 4.8 \mathrm{~mm} ; p<0.001$ or $17.7 \pm 2.7 \mathrm{~mm} /$ $\mathrm{m}^{2}$ vs. $20.4 \pm 3.0 \mathrm{~mm} / \mathrm{m}^{2} ; p<0.001$ ) (Fig. $2 \mathrm{~b}$ and Table 2). Subsequently, CT analysis of the tubular ascending aorta confirmed the dilatation in $\mathrm{D}$ diameter for the AAA group as observed by 2D-TTE imaging (30.8 \pm $3.7 \mathrm{~mm}$ vs. $35.6 \pm 5.1 \mathrm{~mm} ; p<0.001$ and $17.7 \pm 3.0 \mathrm{~mm} /$ $\mathrm{m}^{2}$ vs. $19.3 \pm 3.0 \mathrm{~mm} / \mathrm{m}^{2} ; p=0.045$ ) (Fig. $2 \mathrm{c}$, d and Table 2). In the AAA group, the Pearson's correlation coefficient indicated that higher $\mathrm{D}$ measurement values correlated significantly with the abdominal aortic size $(r=0.40, p<0.001$ and $r=0.37, p<0.001$, respectively; Fig. $3 \mathrm{a}$ and $\mathrm{b}$ ). In addition, we observed 2-4 times more risk of finding abdominal aortic aneurysm by 2D-TTE in patients with a D value of $\geq 33 \mathrm{~mm}$ (OR 4.68, CI 2.18-10.25, $p<0.001$, Fig. 3c) or an index $\geq 19 \mathrm{~mm} / \mathrm{m} 2$ (OR 2.63, CI 1.21-5.62, $p=0.02$, Fig. 3d). Multiple logistic regression analysis revealed that age (OR 1.09, CI 1.03-1.17, $p=0.013$ ), gender (OR 0.12, CI $0.30-0.47, p=0.002$ ), tubular ascending aorta size (D diameter, OR 1.46, CI 1.18-1.82, $p<0.001$ ), and
LVESD (OR 1.24, CI 1.05-1.45, $p=0.009$ ) were the independent predictors of AAA (Table 3).

\section{Discussion}

Abdominal aortic aneurysm is a progressive condition with an increased risk of aortic dissection and mortality $[8,14]$. In this study, our results indicate that 2D-TTE imaging is comparable to CT methodology for measuring and estimating ascending aorta diameters during routine echocardiographic examination. Routine 2DTTE procedures include, but are not limited to, initial and supplemental tests, evaluation of end organ damage (e.g.: hypertension, diabetes mellitus), evaluation of cardiac and aortic structure and function (e.g.: left atrial appendage, left ventricular hypertrophy and diastolic dysfunction, prosthetic heart valves, paravalvular abscesses, patients on ventilators, or with chest wall injuries), intraoperative TTE, guidance of transcatheter procedures (e.g.: septal defect closure, or atrial appendage obliteration, transcatheter valve procedures), and critically ill patients [15]. In addition, we show that patients aged over 75 , primarily non-smokers, without known valvular diseases or hemodynamic compromise, but with increased proximal (tubular) ascending aorta (D diameter) during routine echocardiographic measurements, may present with silent AAA. In fact, an increased proximal (tubular) ascending aorta (D diameter) 

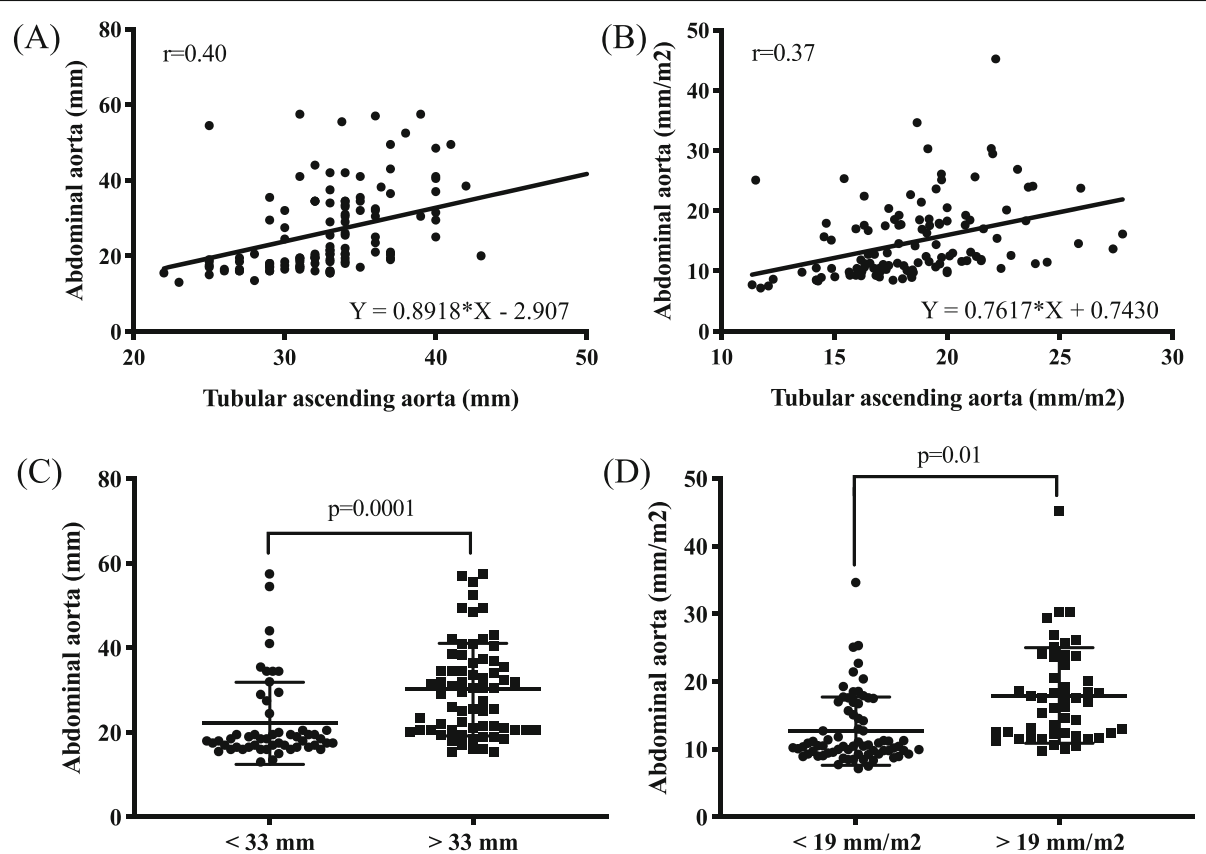

Fig. 3 Association between abdominal aortic size and proximal (tubular) ascending aorta. $\mathbf{a}$ and $\mathbf{b}$ Pearson correlation coefficient of the tubular ascending aorta (D diameter), $\mathrm{mm}(r=0.40, p<0.001)$ and $\mathrm{mm} / \mathrm{m}^{2}(r=0.37, p<0.001)$, by CT. Abdominal aortic diameter threshold for the $D$ measurement, (c) $\mathrm{mm}$ and $(\mathbf{d}) \mathrm{mm} / \mathrm{m}^{2}$, by 2D-transthoracic echocardiography

represents an independent predictor of a silent AAA with a threshold of $\geq 33 \mathrm{~mm}$ or $\geq 19 \mathrm{~mm} / \mathrm{m}^{2}$. We hypothesized that in larger prospective studies, the B diameter can also become significantly dilated. Conversely, the fibrous portion of the $\mathrm{A}$ and $\mathrm{C}$ diameters, can mask progression of the dilatation in those areas.

The abdominal aorta can be relatively easily visualized to the left of the inferior vena cava in sagittal (superiorinferior) subcostal views [16]. Although, 2D-TTE transducers are not optimal for aneurysm detection, detection of an abnormal abdominal aorta can prompt further imaging studies to confirm the presence of AAA. Upon finding of abnormal ascending aorta indices, we recommend screening of the abdominal aorta by means of $2 \mathrm{D}$ TTE, as show to be feasible with minimal additional time and cost compared to separate abdominal

Table 3 Multiple logistic regression analysis showing independent predictors of abdominal aortic aneurism

\begin{tabular}{lllll}
\hline Variables & $\begin{array}{l}\boldsymbol{p} \text { - } \\
\text { value }\end{array}$ & OR & & \multicolumn{2}{c}{$\mathbf{9 5 \%} \mathrm{Cl}$} & \\
\cline { 5 - 6 } & & & Lower & Upper \\
\hline Age (years) & 0.006 & 1.09 & 1.03 & 1.17 \\
Gender, n (\%) & 0.002 & 0.12 & 0.30 & 0.47 \\
Tubular ascending aorta (mm) & 0.001 & 1.46 & 1.18 & 1.82 \\
LVESD (mm) & 0.009 & 1.24 & 1.05 & 1.45 \\
LVEF (\%) & 0.82 & 0.98 & 0.87 & 1.12 \\
\hline
\end{tabular}

OR Odd ratio. CI Confidence interval. LVESD Left ventricle end systolic diameter. LVEF Left ventricle ejection fraction ultrasound examination [16, 17]. Our recommendation extends the current guidelines which recommend 1-time screening for AAA with ultrasonography in men aged 65 to 75 years who have ever smoked [6].

Interestingly, patients with diabetes may have a lower incidence of abdominal aortic aneurysm, although the link between diabetes and AAA development and expansion is unclear $[18,19]$. In our study, we observed a significant number of diabetic patients in the AAA group compared to the control group (no AAA group). This seemingly opposing results can be explained by the fact we did not include within the aims of the study the evaluation of diabetes, hence, patient stratification was not addressed towards that end. To conclude, routine 2D-TTE examination of the ascending aorta is a rapid, accurate and cost-effective tool to identify a 'silent' highrisk AAA population for which further evaluation may be beneficial $[17,20]$. These are particularly relevant when screening for AAA may be overlooked, or screening programs with ultrasonography may not be fully implemented [6, 21]. Clinical awareness, and performance of comprehensive echocardiographic analysis, can help in early diagnosis to reduce AAA-associated risks, reduce mortality and morbidity as well as the economic burden. The limitations of the present study are its nonrandomized, retrospective observational design and the limited number of patients. Selection bias is a limitation of the studies included in the analysis. A larger prospective study must be conducted to monitor and determine 
the presence of AAA in patients with isolated dilated ascending aorta without any associated cardiovascular complications.

\section{Conclusions}

In our study, we observed that ascending aorta indices obtained during routine 2D-TTE in asymptomatic patients, without known valvular diseases or hemodynamic compromise, can indicate the presence silent AAA. Hence, we recommend a review of current recommendations and expand AAA screening to routine 2D-TTE.

\section{Abbreviations}

2D-TTE: 2-Dimensional transthoracic echocardiography; AAA: Abdominal aortic aneurysm; ANOVA: Analysis of variance; BMI: Body mass index; BSA: Body surface area; Cl: Confidence interval; $\mathrm{CT}$ : Computed tomographic; E/A: Early to late mitral flow; IVS: Interventricular septum; LA Area: Left atrial area; LA-AP: Left atrium anterior-posterior diameter; LA: Left atrium; LVED D: Left ventricle end diastolic diameter; LVEF: Left ventricle ejection fraction; LVESD: Left ventricle end systolic diameter; OR: Odd ratio; PACS: Picture archiving computer system; RA Area: Right atrial area; RVEDD: Right ventricle end diastolic diameter; SD: Standard deviation; SVS: Society for vascular surgery; USPSTF: The current U.S. preventive services task force

\section{Supplementary Information}

The online version contains supplementary material available at https://doi. org/10.1186/s13019-021-01488-w.

\section{Additional file 1.}

\section{Acknowledgements}

Not applicable.

\section{Authors' contributions}

Conceptualization and design, E.G-C., and C.Y.; data acquisition, E.C., M.P., A.O., X.P.; data interpretation, E.G-C., C.Y., V.K., S.B., J.J; first draft preparation, E. $\mathrm{G}-\mathrm{C}$. which was then refined based on input and comments from the rest of the authors. E.G-C., C.Y., E.C., A.O., V.K., X.P., M.P., S.B., and J.J., approved the final version to be published.

\section{Funding}

Not applicable.

\section{Availability of data and materials}

The datasets used and/or analysed during the current study are available from the corresponding author on reasonable request.

\section{Declarations}

Ethics approval and consent to participate

The study protocol adhered to the Declaration of Helsinki and was approved by the institutional review board of Barzilai Medical Center (BRZ-0090-20).

\section{Consent for publication}

Not applicable.

\section{Competing interests}

The authors declare that they have no competing interests.

\section{Author details}

${ }^{1}$ Cardiology Department, Barzilai Medical Center Campus, Barzilai University Medical Center, Ben-Gurion University, Ashkelon, Israel. ²Department of Medical Imaging, Barzilai University Medical Center, Ben-Gurion University, Ashkelon, Israel.
Received: 16 January 2021 Accepted: 6 April 2021

Published online: 23 April 2021

\section{References}

1. Kent KC, Zwolak RM, Egorova NN, Riles TS, Manganaro A, Moskowitz AJ, et al. Analysis of risk factors for abdominal aortic aneurysm in a cohort of more than 3 million individuals. J Vasc Surg. 2010;52(3):539-48. https://doi. org/10.1016/j.jvs.2010.05.090.

2. Khashram M, Jones GT, Roake JA. Prevalence of abdominal aortic aneurysm (AAA) in a population undergoing computed tomography Colonography in Canterbury, New Zealand. Eur J Vasc Endovasc Surg. 2015;50(2):199-205. https://doi.org/10.1016/j.ejvs.2015.04.023.

3. Forsdahl SH, Singh K, Solberg S, Jacobsen BK. Risk factors for abdominal aortic aneurysms. Circulation. 2009;119(16):2202-8. https://doi.org/10.1161/ CIRCULATIONAHA.108.817619.

4. Ailawadi G, Eliason JL, Upchurch GR. Current concepts in the pathogenesis of abdominal aortic aneurysm. J Vasc Surg. 2003;38(3):584-8. https://doi. org/10.1016/S0741-5214(03)00324-0

5. Lederle FA. The aneurysm detection and management study screening program. Arch Intern Med. 2000;160(10):1425-30. https://doi.org/10.1001/a rchinte.160.10.1425.

6. Owens DK, Davidson KW, Krist AH, Barry MJ, Cabana M, Caughey AB, et al. Screening for abdominal aortic aneurysm. JAMA. 2019;322(22):2211. https:// doi.org/10.1001/jama.2019.18928.

7. Carnevale ML, Koleilat I, Lipsitz EC, Friedmann P, Indes JE. Extended screening guidelines for the diagnosis of abdominal aortic aneurysm. J Vasc Surg. 2020;72(6):1917-26. https://doi.org/10.1016/j.jvs.2020.03.047.

8. Singh K. Prevalence of and risk factors for abdominal aortic aneurysms in a population-based study : the Tromso study. Am J Epidemiol. 2001;154(3): 236-44. https://doi.org/10.1093/aje/154.3.236.

9. Elefteriades JA, Farkas EA. Thoracic aortic aneurysm. J Am Coll Cardiol. 2010; 55(9):841-57. https://doi.org/10.1016/j.jacc.2009.08.084

10. Chaikof EL, Dalman RL, Eskandari MK, et al. The Society for Vascular Surgery practice guidelines on the care of patients with an abdominal aortic aneurysm. J Vasc Surg. 2018;67(1):2-77.e2. https://doi.org/10.1016/ j.jvs.2017.10.044

11. Moll FL, Powell JT, Fraedrich G, Verzini F, Haulon S, Waltham M, et al. Management of Abdominal Aortic Aneurysms Clinical Practice Guidelines of the European Society for Vascular Surgery. Eur J Vasc Endovasc Surg. 2011; 41:S1-S58. https://doi.org/10.1016/j.ejvs.2010.09.011.

12. Lang RM, Badano LP, Mor-Avi V, et al. Recommendations for cardiac chamber quantification by echocardiography in adults: an update from the American society of echocardiography and the European association of cardiovascular imaging. J Am Soc Echocardiogr. 2015;28(21):1-39.e14. https://doi.org/10.1016/j.echo.2014.10.003

13. Evangelista A, Flachskampf FA, Erbel R, Antonini-Canterin F, Vlachopoulos C, Rocchi $\mathrm{G}$, et al. Echocardiography in aortic diseases: EAE recommendations for clinical practice. Eur J Echocardiogr. 2010;11(8):645-58. https://doi.org/1 0.1093/ejechocard/jeq056.

14. Gallego-Colon E, Jafari J, Yosefy C. Extensive aortic dissection from aortic root to iliac artery. CASE. 2020;4(4):226-9. https://doi.org/10.1016/j. case.2020.04.003.

15. Hahn RT, Abraham T, Adams MS, Bruce CJ, Glas KE, Lang RM, et al. Guidelines for performing a comprehensive transesophageal echocardiographic examination: recommendations from the American Society of Echocardiography and the Society of Cardiovascular Anesthesiologists. J Am Soc Echocardiogr. 2013;26(9):921-64. https://doi. org/10.1016/j.echo.2013.07.009.

16. Gentille-Lorente DI, Salvadó-Usach T. Screening for abdominal aortic aneurysm by means of transthoracic echocardiography. Rev Española Cardiol (English Ed. 2011;64:395-400. doi:https://doi.org/10.1016/j.rec.201 0.11 .008 .

17. Ruggiero M, Lenti ML, Cavallari D, Dicillo CP, Mascolo AR, Musci S, et al. Screening for abdominal aortic aneurysm during transthoracic echocardiography. A prospective study in 1202 consecutive patients at high risk: incidence, correlation with risk factors, feasibility, diagnostic accuracy, and increase in echocardiography tim. G Ital Cardiol (Rome). 2006;7(3):217-23.

18. Rango P, De L, Farchioni BF, Lenti M. Diabetes and abdominal aortic aneurysms. Eur J Vasc Endovasc Surg. 2014;47(3):243-61. https://doi.org/10.1 016/j.ejvs.2013.12.007. 
19. Shantikumar S, Ajjan R, Porter KE, Scott DJA. Diabetes and the abdominal aortic aneurysm. Eur J Vasc Endovasc Surg. February 2010;39(2):200-7. https://doi.org/10.1016/j.jvs.2009.10.014.

20. Argyriou C, Georgiadis GS, Kontopodis N, Pherwani AD, van Herwaarden JA, Hazenberg CEVB, et al. Screening for abdominal aortic aneurysm during transthoracic echocardiography: a systematic review and meta-analysis. Eur J Vasc Endovasc Surg. 2018;55(4):475-49. https://doi.org/10.1016/j.ejvs.2018. 01.003 .

21. Carino D, Sarac T, Ziganshin B, Elefteriades J. Abdominal aortic aneurysm: evolving controversies and uncertainties. Int J Angiol. 2018;27(02):058-80. https://doi.org/10.1055/s-0038-1657771.

\section{Publisher's Note}

Springer Nature remains neutral with regard to jurisdictional claims in published maps and institutional affiliations.

Ready to submit your research? Choose BMC and benefit from:

- fast, convenient online submission

- thorough peer review by experienced researchers in your field

- rapid publication on acceptance

- support for research data, including large and complex data types

- gold Open Access which fosters wider collaboration and increased citations

- maximum visibility for your research: over $100 \mathrm{M}$ website views per year

At BMC, research is always in progress.

Learn more biomedcentral.com/submissions 